\title{
Accurately Grasp The Main Characteristics of The Cultivation of Socialist Core Values in Colleges and Universities in The Internet Era
}

\author{
Chen $\mathrm{Yu}^{1, \mathrm{a}}$, Wang Jiajia ${ }^{1, \mathrm{~b}}$ \\ ${ }^{1}$ Taizhou Polytechnic College, Jiangsu Taizhou, China, 225300 \\ axiaoyueryuchen@163.com_bwangjiajia_99@163.com
}

Keywords: Internet plus, core values, main characteristic.

\begin{abstract}
The cultivation of core values in the Internet plus age requires an accurate grasp of its main characteristics to ensure effectiveness: the complexity of the process and the flexibility of its advance, the consistency of direction and the diversity of advances, the totality of planning and the synergy of advancing together, the inherent of regularity and the comprehensiveness of innovation.
\end{abstract}

\section{Introduction}

With the development of information technology, all kinds of new media platforms are emerging, and the role of traditional media is declining, which brings great challenges to the cultivation and practice of socialist core values in colleges and universities. Therefore, how to accurately grasp its main characteristics, integrate high efficiency, reasonable allocate the limited resources, the online and offline effective convergence, organic integration, force in the same direction, resonance with same frequency, it is particularly urgent and extremely important. Otherwise, the mainstream platform will gradually be marginalized, the role of traditional media will be decaying accelerated, the inherent position will be lost constant, the network platform will become more fragmented, the role of emerging media will become weaker and weaker, and the new position will be difficult to occupy. As a result, the traditional platforms and methods do not work, the emerging platforms and methods do not use, and the effective cultivation and practice of the core values of socialism are even more impossible. They can only be empty words and become mere formality. It is very difficult to put them into practice and achieve practical results, just wasted human, material, financial, and energy.

\section{Deeply understand the complexity and the variety in the progress of the cultivation and practice of socialist core values in the Internet plus age}

The ultimate purpose of carrying out the education of socialist core values is to complete the internalization and externalization of the core values, and make them become the firm belief in the hearts, the external instinctive reactions and the explicit conscious actions of these living people. However, the process of internalization and externalization is extremely complicated, and it must go through repeated, advance with twists and turns, and it cannot be achieved overnight, not to mention once and for all. After all, the object of socialist core values education is the living person, some different individuals, not a cold thing can be placed at will, as long as it does not move it will not change significantly. Each individual has a unique appeal. These demands, which are unreasonable or some irrationality, have been nurtured for a long time and difficult to overcome, but they must be pointed out and corrected in a timely manner, and others are reasonable and require our immediate attention and positive response, we ought to help them strengthen and consolidate. Especially in the age of the Internet plus, the various modes of communication, the diversity of value choices, the variety of ideas, all kinds of reasonable, unreasonable and totally unreasonable phenomena are sweeping in all kinds of values rolling in everywhere. The mixture of fish and eyes makes people dizzying and dazzling, which brings great impact to teachers and students in colleges and universities, and further exacerbates this complexity.

At the same time, from the law of human growth and development, the internalization of values is a process of self-consciousness awakening and value judgment. To successfully complete this 
process and to establish a correct value judgment, we need both consciousness and ability, but the formation of consciousness and ability varies from person to person. It requires both clear and effective education guidance and self-reflection and consolidation. In particular, before fully formed, it is very fragile, it could be destroyed by outside interference, even if really formed, it must be highly valued, and it must always be concerned and guided, carried out education repeatedly, constantly consolidate and strengthen, promote steady promotion, must not have the idea of one-step. Therefore, the so-called "random flowers gradually charming eyes", it is exactly when it comes to chaos. To successfully accomplish the internalization and externalization of core values, we must take the all-round development of one by one different individuals, that is, people in reality, as the fundamental orientation, fully recognize the complexity of the process and the tortuosity of the realization, timely put the record straight, and release the doubts. And through solid and effective measures to guide and correct unreasonable demands, fully concern and take care of reasonable demands, so that their hearts are always full of positive energy, the main melody is high.

\section{A clear understanding of the consistency of direction and diversity of advances to socialist core values in the Internet plus era}

The present era, is a time peoples' work, life, study rhythm change fast, is a time of information explosion. College campuses are by no means pure places for study and study. Not only do they learn and live (and sometimes work) mixed, but all kinds of information also mix with each other, impinge on each other and interfere with each other. We may have been busy studying one minute, but worrying about life in the next. The various themes that foster core values are diluted and the effects are greatly compromised. If the various educational forms and thematic activities are inherently lacking in internal consistency and relevance, the function and effectiveness of education will be seriously diminished. The influence on teachers and students, especially young college students, will be weakened obviously, and the effect is quite limited. Unfortunately, this is also a true portrayal of the core values that some colleges and universities cultivate. Therefore, it is necessary to clearly define the overall objectives, sub-objectives, long-term goals and stage goals, main objectives, secondary goals, direct goals and indirect goals for the cultivation and practice of socialist core values. According to the specific target to be achieved, the corresponding strategy is adopted to determine the functional orientation of the specific way, point along the same direction to ensure the successfully arrival of the predetermined end.

\section{Attach great importance to the wholeness of planning and synergy of advancing together to cultivation and implementation of socialist core values in the Internet age}

The cultivation and practice of socialist core values is a complex systematic project, which needs to be whole planned and coordinated. Some colleges and universities obviously lack top-level design, which belongs to form is dispersed and spirit is more scattered, far from coordinated combat. Some colleges and universities have the top level design, the specific carrier, method, means and path are still fragmented, scattered, and do not respond to each other, but on the surface, it is complete in form. It belongs to form is not dispersed but spirit is scattered. It can not form a unified organic whole with close internal relations, and there is no way to cooperate with them. Although some colleges and universities have done a good job at the top level, the efforts and methods of the promotion are deficient, and they can not achieve the effect of synergy and progress objectively.Especially in today's Internet plus era, with the continuous upgrading of technological means, a variety of Internet products are emerging, the connection and integration of the Internet and real life are becoming closer and closer, and the scope of coverage is becoming more and more extensive, the degree of integration is getting deeper and deeper. Although all walks of life have fully realized the importance of Internet platform and taken certain measures, it has become a universal phenomenon to use the Internet to build socialist core values. 
It is undeniable, however, that the methods and means used by the vast majority of the units are not rich enough, with a single platform, a single form, a monotonous content, and disorderly, often isolated. Group effect and accumulation effect, magnetic field effect and diffusion effect can not be formed effectively. In the end, some colleges and universities already know what to use, but there is still a long way to use good. There are even some colleges and universities to be partial and to make up the numbers. Only push the relevant news on WeChat, they think that they have used the Internet platform to cultivate socialist core values, floating on the surface. There is basically no real effect. Therefore, it is necessary to further strengthen the concept and systematic thinking of deep farming, focus on the whole, collaborate with one another, give a comprehensive strategy, advance systematically, and make every move, every activity, every education, every carrier establish strict logical relations, parallel or complementary, consolidate or strengthen, which can orderly realize the scheduled function, play its due role.

\section{Paying full attention to the inherent regularity and the comprehensiveness of innovation of the cultivation and practice of the socialist core values in the Internet age}

The ultimate goal of school education is to make students master all kinds of knowledge and learn the methods of studying nature and human society through various forms of educational practice, so as to form their own knowledge system, construct and perfect their own world view, life view and values view. The formation of the "three views" mainly depends on two ways: one is to gain direct experience through personal practice, and the other is to gain indirect perception through extensive study. The two approaches, especially the latter, are highly compatible with the main forms of schooling. Therefore, carrying out the cultivation of core values is not only the natural mission of colleges and universities, but also their natural advantages. What colleges and universities need to do is to choose good education content and adopt the right education method by adhering to the fundamental goal of internalization and externalization of socialist core values. ${ }^{[1]}$ At present, there are some problems in the core values education in many colleges and universities. Even when the core values are mentioned, there is a feeling that a mistake will be criticized. There is an instinctive negative emotion and a negative heart in the mind. The basic reason is that the selected content is not good and the methods adopted are not used. The ancients said: "from different sides, the distance and the height are different." Everything is different from the different angles. This is the basic law of understanding things. To cultivate the socialist core values, we should follow the objective law, and be good at introducing from different levels and different angles, using different ways and different patterns to introduce, interpret to the students, rather than empty preaching and rigid indoctrination.

The future has come, east and west, only changes are not change. In order to achieve this goal, we must constantly bring forth the new through the old, especially in the Internet plus age, the form which lack of content support, will be a boring shell, with no fresh, no vitality and no attraction. From a physical point of view, the world is moving and constantly changing. But through the phenomenon to see the essence, the change is the appearance, the invariant is the law. The cultivation of core values must also firmly grasp the changes and invariance of the core values, new and permanent new, learning from the past and the present, and from the foreign, conscientiously following the existing laws, constantly exploring new laws, and carefully selecting the positive educational content from the past and the present, the eastern and western countries, and actively learn from the widespread influence of the dissemination methods, both carry forward and identify, both sublation and inheritance, take its new essence, discard its obsolete dregs, and finally achieve the use of the past for the present, and foreign use for the Chinese.

In short, whether classical, eastern, or modern, western, as long as they are elements of positive significance to the cultivation of core values, as long as they are beneficial to the cultivation of core values, they should be "brought in" in time. According to the request of General Secretary Xi Jinping, "When learning, researching, application, we should adhere to the past for the present, bring forth and new through the past, combined with the new practice and the requirements of the times to make a correct choice." ${ }^{[2]}$ 
That is to say, we should comprehensively reform and upgrade according to the needs of the times, interpret and inculcate with more angles, levels, ways and patterns, and promote the core value deeply and faithfully. At the same time, only by taking all the classic outstanding achievements and methods as the fundamental support, continuously increasing the innovation strength and inserting the wings of the Internet, can we make it re-radiate strong vitality and fully demonstrate the valuable value of the times. Continuously provide the source of water for the cultivation of core value.

\section{Acknowledgement}

This research was financially supported by the Special Project on ideological and political work of philosophy and Social Sciences Research in Jiangsu Province(2017SJBFDY683), and the Key projects of Scientific Research Foundation of Taizhou Vocational and Technical College(TZYKYZD-17-4).

\section{References}

[1] Liu Hongyi. Cultural Education[M]//Yu dianli. Education: Cultivate human nature, cultural man. Beijing: Commercial Press, 2012: 11-14.

[2] Xi Jinping. Xi Jinping on governing the country(Volume II)[M]. Beijing: Foreign language publishing house, 2017: 313 . 